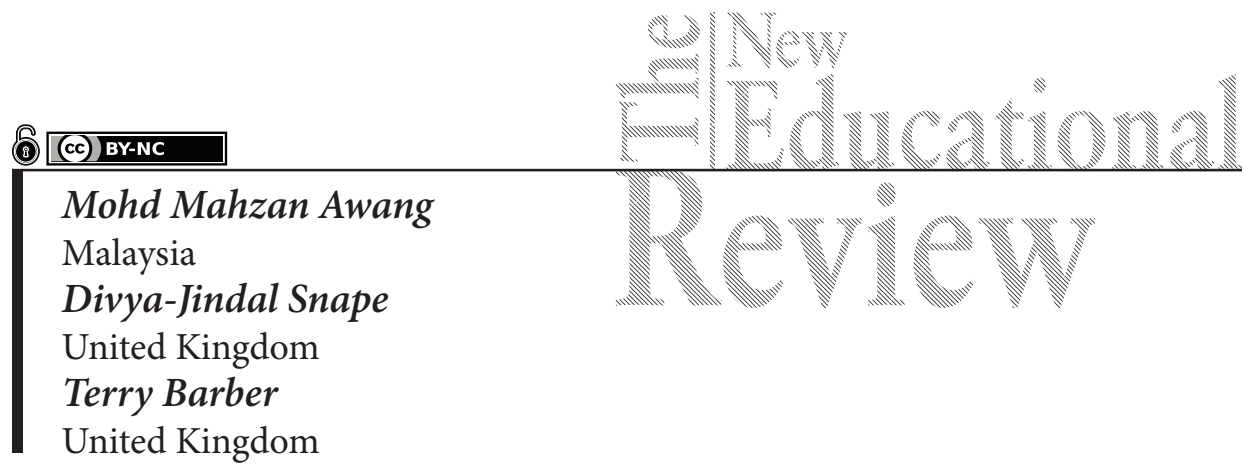

\title{
A Systematic Review of Theoretical Foundations for Pedagogical Strategies to Promote Positive Behavior
}

DOI: 10.15804/tner.2019.58.4.10

\begin{abstract}
This study analysed the theoretical foundations utilised by past empirical research in order to understand the pedagogical strategies used in schools for promoting positive behaviour. The analyses also include how pedagogical theories underpinned past research on positive behaviour enhancement. Samples for this study were academic papers obtained from four main databases: the Australian Education Index, British Education Index, ERIC (Educational Research Information Centre) and Scopus. By using a systematic review technique, a total number of 143 papers were found to be relevant for further analysis. Results revealed that four theoretical models dominate the studies examined, namely Applied Behavioural Analysis, Social Capital theory, Culturally Responsive Classroom Management, and Ecological Systems theory. This study recommends understanding of those theories is important in designing modules for positive behaviour enhancement in schools.
\end{abstract}

Key words: positive behaviour enhancement, pedagogical strategies, systematic review, theories 


\section{Introduction}

The importance of positive behaviour enhancement may be seen as grounded in the United Nations Convention on the Rights of the Child (1990). The convention states that all governments should protect children from harm (Article 36), dangerous drugs (Article 33), sexual abuse (Article 34) and abduction (Article 35). According to this convention, school pupils should be treated with respect and have the same rights regardless of their ethnic background and their needs (ordinary or disability). Children should be part of the decision-making regarding their rights (Articles 12-15, 17). They should not be imprisoned for breaking the law because they are not mature enough to make their own way in the world, and they should not be treated cruelly (Article 37) as they need correction more than punishment. Although the convention is not part of a binding international law, it provides a general framework and a common standard of human rights for all countries. This means that any educational policy throughout the world should concur with this international framework. However, previous research shows that the convention has not fully influenced educational policy in some countries. For instance, the use of corporal punishment in 22 states in the USA (Owen, 2005) and in Malaysian schools is contrary to Article 37. It is therefore important to understand the rationale behind government policy.

\section{Pedagogical Strategies for Excellent Teaching}

According to the Malaysian model, an effective teacher may become an excellent teacher if they excel in six key criteria that are (1) demonstrates good behaviour; an ethical teacher; a role model, (2) expert in his/her subject area; expert in teaching and learning; has excellent time management; has excellent resource management; is able to identify pupils' needs and problems; is very informative; and has excellent information technology skills, (3) is able to improve pupil learning in line with the National Educational Philosophy, (4) is an excellent communicator; is competent to deliver ideas; and is an effective communicator, (5) has clear vision, is proactive, shows initiative, is responsive and innovative, (6) is competent to generate new ideas in education and happy to share their knowledge and skills. He or she should be able to integrate counselling skills, such as problem-solving techniques, in their daily interactions with pupils. These models outline the definition of effective (or excellent) teachers from the government's perspectives. However, it can be argued 
that these prescribed attributes of effective teachers are too idealised and vague, and seem to be unrealistic.

\section{Methodology}

\section{Aims of the Study}

This study aimed to find what are the theoretical foundations utilised by past empirical research in understanding pedagogical strategies for promoting positive behaviour at school level. Indeed, the study will examine how those theories are used in research on positive behaviour enhancement.

\section{Method}

The current study utilised the method of systematic review of contemporary journal papers (2005-2011) from four main databases, namely the Australian Education Index, British Education Index, ERIC (Educational Research Information Centre) and Scopus. Table 1 shows the American and British English keywords that were used in combination to search these databases.

Table 1. Keywords search of abstract

\begin{tabular}{|c|c|c|}
\hline Keyword 1 & Keyword 2 & Keyword 3 \\
\hline \multirow{8}{*}{$\begin{array}{l}\text { positive behavior } \\
\text { (or positive behaviour) }\end{array}$} & Enhancement & strategies/school \\
\hline & Support & school \\
\hline & Cultivation & \\
\hline & Development & \\
\hline & Strategies & \\
\hline & Techniques & \\
\hline & Encouragement/Encouraging & \\
\hline & Management & \\
\hline \multirow{3}{*}{$\begin{array}{l}\text { negative behavior } \\
\text { (or negative behaviour) }\end{array}$} & Prevention & \\
\hline & Discouraging & \\
\hline & Stopping & \\
\hline classroom management & school & \\
\hline discipline/disciplinary strategy & & \\
\hline
\end{tabular}

In order to confine this study to current developments in positive behaviour enhancement strategies, only papers published between 2005 and 2011 were reviewed. In addition to the aforementioned sources, some grey literature was 
also included. A total of 1634 relevant papers published between 2005 and 2011 were obtained from the four databases: 950 papers from the Scopus database; 99 papers from the British Education Index database; 340 papers from the Australian Education Index; and 245 papers from ERIC. All papers that conformed to the following selection criteria were included in the review. Papers had to be written in the English language and had to include participants either from secondary schools or young people aged between 13 and 18 years old. Papers involving participants from both primary and secondary schools were also included in this review. However, papers were not reviewed if they only included primary school pupils, children from kindergarten or participants aged less than 12 years old. This criterion was used because pupils from primary schools have less challenging behaviour compared to secondary school pupils (Theriot \& Dupper, 2010). In order to obtain a greater understanding of this subject, relevant discursive papers (review papers) were also included. Papers were excluded if they included participants with special needs, such as autism, visual or hearing impairment, or other disabilities, as these pupils may exhibit different behaviours due to their limited abilities in communication and/or physical movement and, therefore, intervention strategies for this group may also differ. Finally, papers were not reviewed if they were written in languages other than English.

\section{Data Analysis}

A total of 143 relevant papers were identified, including 106 papers from Scopus, nine papers from the British Education Index database, 12 papers from the Australian Education Index, and 16 papers from ERIC. A detailed review of these papers was conducted to investigate: methodological considerations in researching positive behaviour enhancement strategies; theoretical considerations; conceptualisation of positive and negative behaviour; strategies used for promoting positive behaviour; strategies currently perceived to be effective; and the relationships between social interactions and human behaviour.

\section{Results and Discussion}

The 143 papers reviewed include 113 research-based papers and 30 discursive papers. Most of the research-based papers employed quantitative methods $(n=62)$ rather than qualitative methods $(n=28)$, mixed-methods $(n=12)$, longitudinal studies $(n=6)$, or experimental studies $(n=5)$. Whilst quantitative studies provide evidence of relationships between tested variables, they provide limited in-depth 
descriptions of participants' beliefs and attitudes toward certain positive behaviour enhancement strategies. Further, in-depth descriptions of this topic seem to be biased, as many previous studies investigated adults' perspectives rather than young people's views. For instance, from a total of 28 qualitative papers, $64 \%(\mathrm{n}=18)$ solely included adult participants, including teachers, counsellors, principals and parents. Only six papers investigated pupils' perspectives, and four studies included both adults and children. For instance, Freeman et al. (2009) explored notions of bullying and the support required from pupils from 26 European countries, and found that there is little support for promoting pupils' well-being and preventing bullying in school (Freeman, et al., 2009). However, it could be argued that pupils who participated in that study may have had no experience in obtaining support from professionals. Further, the actual actions used by teachers for promoting pupils' well-being and preventing bullying in that school are unknown. Another paper investigating the connection between religious norms and concepts of positive and negative behaviour was solely based on pupils' self-reporting, without cross checking with other sources (Hardy \& Carlo, 2011), and therefore the validity of the results is questionable. This suggests that gathering from a single group or source may cause bias. Papers that include both professionals' and pupils' perspectives are more convincing. For instance, Schedin (2005) included both teaching professionals and pupils when investigating expectations of clients and their career counsellors. Findings from that study revealed that both parties had commonalities and differences that could be used for improving practice.

This review reveals an ambiguity regarding how participants became involved in studies. The majority of papers examined assumed that participants had sufficient knowledge and experience to participate in the studies. However, the small sample sizes used in the papers raises issues of bias and transferability. For instance, in the investigation of pupils' self-concept and motivation in England, Mainwaring and Hallam (2010) included only 25 pupils in the final year of schooling, whereas Lee and Davies (2005) included only 13 pupils in a study of factors associated with the school non-attendance. The small sample sizes of these studies limit the transferability of their results. Therefore, the use of mixed-methods research design and a bigger sample size may be useful for providing a holistic and in-depth understanding of the social phenomena under investigation.

This review found that four theoretical models dominate the studies examined, namely Applied Behavioural Analysis, Social Capital theory, Culturally Responsive Classroom Management, and Ecological Systems theory. 
- Underpinning Theory 1: Applied Behavioural Analysis

The application of behavioural theory has resulted in the formulation of the School-Wide Positive Behaviour Intervention and Support model (Sugai, 2011), which has three levels of prevention: primary, secondary and tertiary. Primary prevention aims to preclude potential problems by letting pupils know expectations for their behaviour. Secondary prevention aims to provide intensive or targeted interventions to support pupils who are not responding to primary prevention efforts. This level focuses on pupils with more serious problems that require more support than other pupils. At the tertiary level, individual treatment includes counselling and a behaviour modification programme.

The current review shows that the School-Wide Positive Behaviour Intervention and Support model is widely used in the USA and Australia. In the USA, nearly 5,000 schools across 40 states have adopted this approach (George \& Kincaid, 2008). A grey literature search carried out using the key phrase "positive behaviour support and intervention" in the ProQuest Education Journals and the ERIC Plus database yielded 2881 dissertations and theses conducted between October 2001 and March 2011. There is a growing interest in Australian schools towards adopting this approach (O'Neill \& Stephenson, 2010). However, discussions of this approach seem to ignore the role of socio-cultural elements that are integral for promoting positive behaviour in multi-ethnic classrooms.

- Underpinning Theory 2: Culturally Responsive Classroom Management This model was introduced by Weinstein, Tomlinson-Clarke and Curran (2004). It proposes that multicultural components have a significant impact on classroom management beliefs and practice, and has five essential elements:

... (a) recognition of one's own ethnocentrism, (b) knowledge of students' cultural backgrounds, (c) understanding of the broader social, economic, and political context, (d) ability and willingness to use culturally appropriate management strategies, and (e) commitment to building caring classrooms (Weinstein, et al., 2004, p. 25).

This model emphasises the importance of a teacher's ability to manage the classroom, to provide more opportunities for pupils to learn new things and to engage them in lessons, regardless of the subject matter being taught (Milner \& Tenore, 2010). Milner and Tenore (2010) stated that the centrality of understanding about the cultural backgrounds, equity, equality, relationships with others, and parent-school involvement significantly contributes to effective classroom management. They debate the extent to which pupils should be encouraged to learn 
about cultural complexity in the classroom. If they are, what strategies should be used in the classroom? Furthermore, are any conflicts raised by this diversity and how should teachers overcome such possible conflict? Bucalos and Lingo (2005) reported that pupils expect teachers to integrate socio-cultural elements into their daily conversations and interactions. However, little is known regarding the ability of teachers to understand other socio-cultural values. In addition, it is illogical for teachers to consider every single aspect of pupils' cultural backgrounds when managing the classroom. Although the issue of practicality in translating this model into practice has been raised, understanding different socio-cultural values is essential in a multi-ethnic classroom.

\section{- Underpinning Theory 3: Social Capital Theory}

The current review found that some papers utilised Social Capital theory to explain positive behaviour enhancement in school. The term "Social Capital" was first time used in 1916 in Hanifan's essay on the school as a community centre. Social Capital theory was developed by Bourdieu (1986) and later expanded and reformulated by Coleman (1988) and Putnam (2000). Although Bourdieu (1986), Coleman (1988) and Putnam (2000) have different priorities in conceptualising social capital, they agree that social networks are valuable for promoting a better life, well-being, civic trust and a sense of obligation.

Extensive research supports the importance of social networks in developing a stable society. One paper included in this review reported that social capital in the workplace is essential for developing skills, adding new knowledge and promoting a supportive working atmosphere (O’Neill \& Stephenson, 2010). The paper reported that the majority of participants had benefited from attending training sessions and that they therefore had a positive attitude towards professional training. This was supported by another study showing that a social capital network in the workplace is beneficial for promoting a feeling of ownership. Midthassel (2006) suggests that a sense of belonging can be promoted via knowledge sharing among school professionals. Other academic papers report that a lack of social capital networks contributes to self-harming behaviour (Hall and Place, 2010) and victimisation (Gottfredson \& DiPietro, 2011). On the other hand, wide social capital networks promote prosocial behaviour in pupils (Fredricks \& Eccles, 2008). Despite these positive aspects, social capital networks also have negative implications. For example, since social networks are based on a shared common interest, pupils with challenging behaviour may seek friends who have common values and interests, and some social groups influence young people to engage in more negative than positive activities. This explains the formation of a gang 
culture. Therefore, some empirical studies suggest that minimising the radius of social networks is important to keep children safe from criminal activities and violence (Molnar, Browne, Cerda \& Buka, 2005; Molnar, Roberts, Browne, Gardener \& Buka, 2005). This research implies that the value of social capital networks is dependent on the quality of life and environmental factors.

- Underpinning Theory 4: Ecological Systems Theory

Ecological Systems theory (Bronfenbrenner, 1979, 1992) offers a theoretical construct of socio-interactions within and between the following ecological layers: the Microsystem (direct interaction with social agents), the Mesosystem (connection between contexts such as the relation of school experiences to out of school experiences), the Exosystem (indirect interaction with social agents), the Macrosystem (socio-cultural context and system of belief) and the Chronosystem (time dimension).

According to the theory, the Microsystem includes socio-interactions in school, although some papers use this term to describe interactions within/between teachers and pupils in learning activities. For instance, while many papers show that active participation in sport promotes positive behaviour in pupils (Faber, Kulinna \& Darst, 2007; Lumpkin, 2008; Sandford, Duncombe \& Armour, 2008), recent studies show contradictory results (Barnett, 2007; Fredricks \& Eccles, 2008). One paper reported that active participation in sports activities does not necessarily improve positive behaviour, and that a less favourable experience of sport may negatively affect pupils' emotions, behaviour and relationships with peers and adults (Fredricks \& Eccles, 2008). A second study found that sport activities offer both positive and negative effects as engagement in sport promotes prosocial behaviour and develops confidence in pupils; however, being defeated in a game may negatively affect pupils' emotions (Barnett, 2007). This research implies that the investigation of social phenomena in the Microsystem layer provides more information and a better understanding of factors associated with positive behaviour development.

The current review found that the physical environment is a significant contributor to human behaviour. One paper reported that a good infrastructure promotes a positive attitude towards schooling (Kumar, et al., 2008). However, as improving the physical infrastructure is costly, financial support from the government is much needed, and this may be an issue for low-income countries. Yet, promoting positive behaviour is not solely dependent on the physical environment, as various other factors within/between ecological layers are also associated with positive behaviour enhancement. 


\section{Contributions to Pedagogical Practices of Promoting Positive Behaviour}

The consistent message from this review is that many theoretical perspectives assert that certain strategies might be more effective than others. However, a specific analysis found that there are two dimensions to this assertion. First, some papers reported strategies which were perceived as effective by the participants. These provided justifications for and explanations of why certain strategies are used by teachers. The second category reported effective strategies based on actual behavioural outcomes. Findings from this category appear more robust than those of the former one. However, both dimensions contribute to a better understanding of strategies that were used in the past.

\section{Conclusions}

This systematic review found that theoretical foundations of positive behaviour enhancement can be divided into two dimensions: encouraging positive behaviour and discouraging negative behaviour. In order to promote positive behaviour, empirical evidence suggests bonding and bridging social capital, whereas to discourage negative behaviour, many papers highlighted reinforcement strategies and punitive discipline, including physical and non-physical punishment. In addition to punishment, intervention programmes are considered to be effective strategies for preventing negative behaviour. Some papers asserted that certain strategies are better and more effective than others. However, it is pertinent to question whether the strategies are truly effective or whether they are rather perceived to be effective. In fact, the effectiveness of certain strategies may be due to other factors.

\section{Acknowledgements}

This paper is based on the large study conducted at a doctoral level. The study was funded by the Ministry of Education, Malaysia and supported by the national grant codes GG-2019-024 and GG-2018-013. 


\section{References}

Barnett, L.A. (2007). "Winners" and "Losers": The effects of being allowed or denied entry into competitive extracurricular activities. Journal of Leisure Research, 39(2), 316-343.

Bourdieu, P. (1986). The Forms of Capital. In J. Richardson (Ed.), Handbook of Theory and Research for the Sociology of Education (pp. 241-258). New York: Greenwood.

Bronfenbrenner, U. (1979). The Ecology of Human Development. Experiments by Nature and Design. Cambridge, Massachusetts and London: Harvard University Press.

Bronfenbrenner, U. (1992). Ecological Systems Theory. In R. Vasta (Ed.), Six Theories of Child Development (pp. 187-249). London and Philadelphia: Jessica Kingsley Publishers.

Bucalos, A.B. and Lingo, A.S. (2005). What Kind of "Managers" Do Adolescents Really Need? Helping Middle and Secondary Teachers Manage Classrooms. Beyond Behaviour, 14(2), 9-14.

Coleman, J.S. (1988). Social Capital in the Creation of Human Capital. The American Journal of Sociology, 94, 95-120.

Faber, L., Kulinna, P.H. and Darst, P. (2007). Strategies for Physical Activity Promotion Beyond the Physical Education Classroom. Journal of Physical Education, Recreation and Dance, 78(9), 27-31.

Fredricks, J.A. and Eccles, J.S. (2008). Participation in Extracurricular Activities in the Middle School Years: Are There Developmental Benefits for African American and European American Youth? Journal of Youth Adolescence, 37, 1029-1043.

Freeman, J.G., Samdal, O., Klinger, D.A., Dur, W., Griebler, R., Currie, D. and Rasmussen, M. (2009). The Relationship of Schools to Emotional Health and Bullying. International Journal of Public Health, 54(SUPPL. 2), 251-259.

George, H.P. and Kincaid, D.K. (2008). Building District-Level Capacity for Positive Behaviour Support. Journal of Positive Behaviour Interventions, 10(1), 20-32.

Gottfredson, D.C. and DiPietro, S.M. (2011). School Size, Social Capital, and Student Victimization. Sociology of Education, 84(1), 69-89.

Hall, B. and Place, M. (2010). Cutting to Cope - A Modern Adolescent Phenomenon. Child: Care, Health and Development, 36(5), 623-629.

Hardy, S.A. and Carlo, G. (2011). Religiosity and Prosocial Behaviours in Adolescence: The Mediating Role of Prosocial Values. Journal of Moral Education, 34(2), 231-249.

Kumar, R., O'Malley, P.M. and Johnston, L.D. (2008). Association Between Physical Environment of Secondary Schools and Student Problem Behaviour: A National Study, 2000-2003. Environment and Behaviour, 40(4), 455-486.

Lee, J. and Davies, J.D. (2005, 27 November-1 December). Those Who Bother and Those Who Don't. Paper presented at the Conference of the Australian Association for Research in Education, Melbourne.

Lumpkin, A. (2008). Teachers as Role Models: Teaching Character and Moral Virtues. Journal of Physical Education, Recreation and Dance, 79(2), 45-49.

Mainwaring, D. and Hallam, S. (2010). 'Possible Selves' of Young People in a Mainstream Secondary School and a Pupil Referral Unit: A Comparison. Emotional and Behavioural Difficulties, 15(2), 153-169. 
Midthassel, U.V. (2006). Creating a Shared Understanding of Classroom Management. Educational Management Administration and Leadership, 34(3), 365-383.

Milner, H.R. and Tenore, F.B. (2010). Classroom Management in Diverse Classrooms. Urban Education, 45(5), 560-603.

Molnar, B.E., Browne, A., Cerda, M. and Buka, S.L. (2005). Violent Behaviour by Girls Reporting Violent Victimization: A Prospective Study. Archives of Pediatrics and Adolescent Medicine, 159, 731-739.

Molnar, B.E., Roberts, A.L., Browne, A., Gardener, H. and Buka, S.L. (2005). What Girls Need: Recommendations for Preventing Violence Among Urban Girls in the US. Social Science and Medicine, 60, 2191-2204.

O'Neill, S. and Stephenson, J. (2010). The Use of Functional Behavioural Assessment for Students with Challenging Behaviours: Current Patterns and Experience of Australian Practitioners. Australian Journal of Educational and Developmental Psychology, 10, 65-82.

Putnam, R.D. (2000). Bowling Alone: The Collapse and Revival of American Community. New York: Simon and Shuster.

Sandford, R.A., Duncombe, R. and Armour, K.M. (2008). The Role of Physical Activity/ Sport in Tackling Youth Disaffection and Anti-social Behaviour. Educational Review, 60(4), 419-435.

Schedin, G. (2005). Similarity of Interpersonal Behaviour in Career Counselling. International Journal for Educational and Vocational Guidance, 5, 37-55.

Sugai, G. (2011, 25 th of August). [What is the Foundation of Positive Behaviour Support?]. Theriot, M.T. and Dupper, D.R. (2010). Student Discipline Problems and the Transition From Elementary to Middle School. Education and Urban Society, 42(2), 205-222.

United Nations High Commissioner for Human Rights. (1990). Convention on the Rights of the Child. Retrieved $16^{\text {th }}$ of March, 2011, from http://www2.ohchr.org/english/law/ crc.htm 